\title{
Assessing hospital readiness for radio frequency identification device implementation in Iran: a conceptual model
}

\author{
Malihe Sadeghi',2, Pakzad Rahmati', Zahra Ramezani Pour³, Elham Goharinejad ${ }^{3}$, Mehdi Kahouei*
}

\begin{abstract}
Background: To avoid possible failures and ineffective use of economic resources, necessary infrastructure must be provided before implementing new technologies in a developing country like Iran.

Objectives: To assess the degree of readiness for implementing a radio frequency identification device (RFID) system in hospitals in Iran.

Methods: We adopted a descriptive design and structural equation modeling (LISREL statistical software package) to analyze data collected from the hospitals affiliated with the Semnan University of Medical Sciences. All managers, physicians, residents, nurses, and staff members of the medical records and information technology sectors participated in this study. A questionnaire was designed by the investigators to collect ideas from the participants about organizational readiness, cultural readiness, and human resource readiness in implementing RFID.

Results: We found a significant positive correlation between the variables studied. Human resource readiness significantly predicted RFID implementation, with cultural readiness playing the role of a mediator variable. Cultural readiness itself was influenced by organizational readiness $(P<0.01)$. We found 0.346 (standard deviation: 0.374$)$ changes in an arbitrary unit of the possibility of RFID implementation was attributed to human resources and cultural readiness.

Conclusions: Paying attention to cultural factors, which play an important role in implementing technological projects such as RFID in developing countries like Iran, can reduce the risk of failure. Hospitals should strengthen organizational factors and improve the support of top rank managers when implementing technological projects. By so doing, they will promote cultural readiness, prepare human resources, and win the cooperation of personnel for such projects.
\end{abstract}

Keywords: health plan implementation; latent class analysis; radio frequency identification device; set (psychology)

Information and communication technology (ICT) is considered as an important element of the economic growth of countries that can improve the living standards of people [1]. Radio frequency identification (RFID) is a type of ICT [2] that is used as a valuable tool for automatic identification [3]. RFID systems use radio waves for collecting and transferring data, without any human intervention [4].

* Correspondence to: Mehdi Kahouei, Social Determinant of Health Research Center, School of Allied Medical Sciences, Semnan University of Medical Sciences, Semnan, Iran 3513138111, email: mkahouei@semums.ac.ir

'Health Information Technology Department, School of Allied Medical Sciences, Semnan University of Medical Sciences, Semnan, Iran

${ }^{2} S c h o o l$ of Health Management and Information Sciences, Iran University of Medical Sciences, Tehran, Iran

${ }^{3}$ Student Research Committee, School of Allied Medical Sciences, Semnan University of Medical Sciences, Semnan, Iran

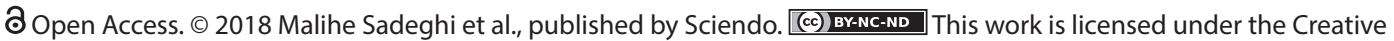
Commons Attribution NonCommercial-NoDerivatives 4.0 License. 
RFID is a relatively established technology, which is rapidly becoming a standard measure for tracking property and managing staff members [5]. RFID is used in various domains, such as supply chain management, retail, aircraft maintenance, anticounterfeiting, and baggage handling [6]. RFID technology has also been introduced into the health sector and because of its unique features it has become a favored technology [7]. Its main uses are the identification of objects and related information [8]. It is also used to track medical equipment, control special hospital equipment, collect information from patients, track patients while revealing and confirming identity, and automatically collect and transfer data $[9,10]$. RFID has the advantage of reducing the risk of errors made by employees [11].

In 2 hospitals in Singapore, RFID was used to reduce the spread and transmission of infectious disease in pandemics of severe acute respiratory syndrome. RFID, as a newly implemented technology, assisted these hospitals to guarantee the safety of patients, staffs, and visitors by identifying and tracing infected persons. Many pharmaceutical companies install RFID tags on packages of drugs to identify and distinguish genuine medicines and to protect the drugs from theft. RFID is also used to monitor patients to reduce medical errors. For example, RFID technology can be used to match patients and their medical orders or drugs. RFID helps to ensure that the right medication is given to the right patient [12].

Given the advantages of the RFID and because of its farreaching impact on the health industry, organizations and countries (on a broader scale) should adapt themselves to the advantages and speed up the process of using such technologies. To do so, they must prepare appropriate infrastructure to implement these new technologies. The present study aimed to assess the degree of readiness for implementing RFID in hospitals in Iran.

There are certain prerequisites for RFID implementation, including sensors to be attached to patients, staff, medication, and medical assets to be tracked, and connections between hardware. Connections should be made between wireless networks and the existing infrastructural network in hospitals [11].

An RFID system has 3 components: (1) an RFID tag that is attached to an object for identification, (2) an RFID reader that requests the data from the tag, and (3) middleware that processes and stores the information obtained by the readers. This middleware is linked to the tagged object. The RFID system can also be integrated with an information system to prepare smart services based on the data obtained from the middleware [4]. In other words, the RFID middleware is used to process and transfer RFID-based data into specific back-end hospital systems (hospital information systems (HIS), clinical management systems (CMS), enterprise resource planning systems (ERP)), where these data are managed to improve the decision-making process $[4,13]$.
Tags can be divided into 2 modes, namely active and passive tags. Active tags have a power source integrated into the tag and actively send a radio frequency (RF) signal to communicate with the RFID reader [14]. In other words, in this mode, the reader is mobile. Staff would use a handheld device (e.g., PDA, mobile phone, laptop) equipped with a reader and a wireless connection. These people holding the RFID reader tool actively collect the data whenever they are close to the tag [15]. Passive RFID technology provides small-sized tags, suitable for objects with different shapes and sizes that operate without batteries and require no maintenance [16]. Passive tags are powered by interrogation signals from the reader and they are connected through either near- or far-field connections [14]. In other words, the reader is fixed in this mode. Readers are placed in rooms and corridors to read tags that transfer data through these sites. Once the information is captured from a tagged object, readers send the collected data through an access point (that can be positioned on the wall) via a network to the central medical information system [15]. RFID technology is now a well-known technology and is functional in our everyday life. RFID remains one of the "topten" key technologies [17].

Studies that have focused on the implementation of RFID indicate that this technology brings various benefits such as facilitating workflow in hospitals, reducing workload, increasing interaction between physicians and patients [5], providing easier access to patients' data, providing the opportunity to use hospital equipment more efficiently, reducing the amount of time that patients should spend in hospital sections, making more time for personnel and nurses to attend to their patients' needs, providing the opportunity to control and take care of patients in various hospital sections more efficiently, and integrating processes [18].

Attaran et al. studied opportunities and challenges facing RFID implementation in supply chains and evaluated RFID applications in various industries. In their study, using the data extracted from the literature, they identified a list of 10 benefits or achievements that organizations can realize by adopting RFID in their supply chains; these include quick information retrieval, accurate asset tracking, and reduced operating costs [19].

Conversely, the implementation of RFID has raised some concerns. For example, in some places, the necessary infrastructure for implementing this technology does not exist $[5,20]$. Ebrahimi et al. evaluated the readiness of hospitals affiliated to Shiraz University of Medical Sciences for the implementation of an RFID system. As they reported, the studied hospitals had a moderate level of readiness. According to their findings, many of the studied hospitals were not ready for the implementation of RFID technology; therefore, 
they recommended hospitals to provide a budget, to improve the technical and communicative infrastructures, and to make plans for implementation of this technology [21].

By implementing this technology, personnel and nurses have reported concerns that they will be under excessive surveillance $[5,20]$. Nevertheless, nurses, physicians, and other personnel need to be trained to use RFID [22]. Personnel have also expressed their concerns over their job security, and believe that after the implementation of this technology, they may be redundant. In addition, some patients and visitors do not fully trust RFID and patients resist the use of this technology [18]. Therefore, the implementation of RFID has raised concerns of social and ethical dimensions [23].

Despite that RFID has many capabilities, lack of readiness in its implementation may lead to its weak application and failure. Like any other form of technology, RFID has its advantages and shortcomings. It is necessary to recognize the challenges to use this technology efficiently [24].

Some of the obstacles and challenges in the implementation of RFID in hospitals in South-East Asia were as follows: lack of coordination between different bodies of the government, industries' limitation to adopt RFID technology, lack of information, lack of return on investment, insufficient budget available, lack of internal resources to support the system, inadequate expertise of RFID vendors/consultants, potential risks threatening the nature of a business, rejecting the system because of privacy and security issues, complexity of technology and systems, deficient RFID standards, incomplete RFID technology, dramatic changes made to IT systems, lack of reliability, and lack of security [12].

To implement any kind of technology, it is necessary to consider its infrastructures and required conditions [25]. The successful implementation of RFID requires some preparation [20]. Some of the infrastructures that are required for implementing RFID in healthcare organizations are human, cultural, organizational, technological, informational and communicational, physical, and environmental factors [26].

One of the main reasons for the unsuccessful implementation of developmental plans and new technologies in third world countries is neglecting cultural, social, and human factors. The mismatch between many plans and the environment in which they are implemented is the result of paying improper attention to socio-cultural conditions [27]. For successful implementation of information technology, it is crucial to gain a correct understanding of culture in national, organizational, and group-based levels in information technology studies. Culture plays a significant role in managerial processes that directly or indirectly influence information technology [28]. Accumulating enough cultural knowledge helps managers gain a thorough understanding of the atmosphere that dominates an organization, magnify its strengths, and take steps to eliminate its shortcomings [29].

On the other hand, human resources constitute the designing and processing body of operational systems, hence significantly contributing to organizational changes. Therefore, neglecting human resources leads to undesirable results in projects [30]. Organizational factors constitute another important element that facilitates the implementation of new technologies in an organization [25] and play an integral role in implementing information technology in health systems [31].

Previous research on RFID implementation has paid little attention to some important issues such as human, cultural, and organizational factors in implementing new technologies. It is essential to determine whether hospitals are ready to embrace new technologies. Before implementing a new technology in an organization, it is crucial to make sure that there is sufficient preparation in the organization to successfully apply the new technology. Equally, likely obstacles should be minimized as far as possible. In a developing country like Iran, there is a strong inclination toward the implementation of RFID in the health sector; however, this will have considerable costs. In such a situation, the following questions are raised:

1. Do the hospitals have the necessary infrastructure to successfully implement this new technology?

2. Which areas have the highest degree of readiness for its implementation?

3. How do these various factors influence each other?

\section{Developing hypotheses}

Organizational factors entail features that have a direct relationship with implementation of the technology [25]. Organizational culture is a common and relatively stable pattern of values, beliefs, and essential ideologies in an organization. Making any changes in an organization is only possible through understanding its organizational culture [32]. Culture is the way through which duties are accomplished in an organization and is related to people's behavior and viewpoint [33]. Culture should not be regarded as an aim, but as a means to an aim [34]. In information technology, culture has its own particular definition. To implement any kind of technology, cultural readiness is of particular importance [35]. Because it indirectly influences the successful implementation of information technology [36], organizational culture can be regarded as a mediator variable between cultural, organizational, and human factors in implementing RFID. 
Accordingly, the first hypothesis (H1) is as follows:

There is a relationship between factors connected with organizational and cultural readiness.

In this era of knowledge and information, the human factor is one of the main influential elements and is regarded as a valuable property and asset in an organization. The human factor is the main resource for achieving an organization's goals. Consequently, the factors influencing humans, such as culture, on different forms of technology have received attention. Culture is one of the most comprehensive, influential factors in empowering human resources and guaranteeing their success. It has an effective role in successful implementation of information technology in a particular organization [36]. Culture management should determine a list of appropriate behaviors and then suggest suitable human processes to develop these behaviors [37].

Thus, the second hypothesis (H2) is as follows:

There is a relationship between factors connected to human and cultural readiness.

Organizations exist in a dynamic and active environment and are under the influence of exogenous and endogenous factors [31]. Human resources constitute the main infrastructure in any organization. They are the major elements for the development of an organization or country [38]. If an organization provides necessary conditions to develop the skills and knowledge of its human resources, it can make progress. When human resources are knowledgeable and skillful, they can accumulate other resources for the organization to help the organization develop and achieve its goals [39]. Before developing a strategy for human-related resources, factors such as culture, organizational structure, and leadership style must be taken into consideration [37] because human factors considerably influence technology implementation [38]. As a result, the third hypothesis (H3) is as follows:

There is a relationship between factors connected with human and organizational readiness.

\section{Materials and methods}

\section{Participants and setting}

After obtaining ethical approval from the Medical Ethics Committee of Semnan University (approval no. IR.SEMUMS. REC 93/584227). The present descriptive functional study was conducted in hospitals (Kausar Hospital and Amiralmomenin Hospital) affiliated with the Semnan University of Medical Sciences from May to November 2015 following the principles of the Declaration of Helsinki and its contemporary amendments. The target hospitals are equipped with HIS and electronic medical records. Managers, physicians, residents, nurses, and staff members of the medical records and information technology sectors participated in this study. Thus, no sampling procedure was used. Before conducting the study, all the participants were informed about RFID. We prepared a cover letter describing the purposes of the study. The letter explained that responding to a questionnaire indicated the participants' consent to take part in the research. We assured the participants that all individual responses would be kept confidential.

\section{Questionnaire survey}

A 5-point Likert-type questionnaire was used for collecting data (answers range: very little, little, somewhat, very, and very much). The questionnaire instrument was designed based on the available literature.

There were 28 questions in the survey as follows:

1. How much are you proficient in computer use?

2. How much are you proficient in working with the Internet?

3. To what extent have you been trained on new technologies?

4. As a healthcare provider, how willing are you to attend training courses to obtain skills needed to work with RFID technology?

5. How willing are you to implement this new technology in your workplace in the hospital?

6. Does the utilization of RFID technology improve your work practices?

7. How much individual creativity do you have for the implementation of a new technology or for being innovative in services?

8. How much are you motivated to apply new technologies for the delivery of healthcare services?

9. With the introduction of a new technology, how much are you prone to give priority to collective interests instead of individual interests?

10. To what extent are you committed to your organization (hospital)?

11. How much are you encouraged to use available technologies in your workplace?

12. How much are you flexible to the changes in your work environment (such as the introduction of new information systems for recording patient information, etc.)?

13. With the introduction of RFID technology, how much is your job jeopardized? 
14. With the introduction and utilization of a new technology, how much do you feel free to perform your tasks?

15. How much are you able to perform teamwork with your colleagues?

16. To what extent are you ready to cooperate with other healthcare providers in the implementation and deployment of RFID technology?

17. How much is your hospital committed to implement the 5 -year plan?

18. In your opinion, how much the personnel in your organization are interested in progress and development?

19. With the introduction of a new technology, does your hospital properly change the existing procedures of clinical service delivery?

20. How much does your hospital pay attention to the information technology and its role in improving the quality of service?

21. How much effort is made in your hospital to design new policies and procedures for the implementation of information and communication technology (ICT) in the hospital?

22. How much do senior managers support the implementation of new technologies?

23. In your opinion, how much will senior managers support the implementation of RFID technology?

24. In your opinion, is your hospital able to form executive teams and working groups to implement RFID technology?

25. Are senior managers of hospital able enough to introduce training courses for personnel to gain the necessary skills to work with RFID technology?

26. In your opinion, does the utilization of RFID technology make changes or interrupt other hospital systems?

27. How much is your organization prepared to remove the challenges and obstacles facing the implementation of this technology?

28. In your opinion, to what extent will senior managers understand the early benefits of RFID technology?

To evaluate its content validity index (CVI), the primary questionnaire was reviewed for content validity. The questionnaire was given to 10 experts to obtain their suggestions and comments regarding the aspects of simplicity of questions (SCVI), relationship of questions (RCVI), and clarity of questions (CCVI). Questions with a score $>0.8$ were regarded as suitable. Questions with a score $<0.8$ were removed or rewritten as recommended by the experts, and then they were evaluated by the experts again. Then, the mean scores were calculated and documented. Next, using the suggestions of the experts, the questionnaire was rewritten and became more focused. Then, we piloted the questionnaire on 40 research community selected without preference from various hospitals. Participants in the pilot study were excluded from the main study.

Cronbach's $\alpha$ was used to calculate the reliability of the instruments, with the results indicating indices of $90 \%$ for the entire instrument, $75 \%$ for human resources readiness, $79 \%$ for cultural readiness, and $88 \%$ for organizational readiness. Next, further revisions were made and some statements were rephrased.

The final version of the questionnaire consisted of 2 parts: the first part included demographic items such as age, gender, work experience, and job. The second part included 28 questions in 3 subscales. The first assessed the degree of the participants' computer and Internet skills with 9 questions, inclination toward learning how to work with RFID, willingness to attend training courses, motivation and creativity, ideas about improvement in work experience, and preference for collective (rather than individual) interests. This subscale aimed at measuring the degree of preparation of human resources. The second subscale, which tapped into the degree of cultural preparation with 7 questions, included areas such as participants' commitment to the hospital, flexibility, feeling of freedom, and fear of losing job. Finally, the third subscale with 12 questions measured participants' ideas about the support received from top rank managers, the readiness of the organization to deal with challenges, the hospital's capability to form executive teams and hold relevant training classes, and hospital's capability in reengineering and changing the process of service provision. This subscale concentrated on the degree of organizational readiness.

Lastly, the questionnaire was distributed among the research community $(n=400)$ who were working in hospitals and they were asked to complete the questionnaire.

\section{Data analysis}

SPSS for Windows (version 16) was used to determine descriptive and inferential statistics including regression, Pearson correlation, and Kolmogorov-Smirnov test. To investigate the relationship between factors connected with organizational, human resources, and cultural readiness, a structural equation modeling was run using LISREL (version 8.8).

\section{Results}

Of the 400 questionnaires distributed, 245 were returned to the researchers; a return rate of $61.3 \%$. Based on the collected 
data, 202 of the participants $(82.4 \%)$ were women. Some 119 respondents $(48.6 \%)$ were aged between 25 and 35 and 75 participants $(30.6 \%)$ had $5-10$ years of work experience (Table 1).

We report descriptive statistics (i.e., central tendency and variance) for the 3 variables: human, cultural, and organizational readiness (Table 2). As the Table indicates, the mean for the 3 variables is relatively high.

A Kolmogorov-Smirnov test was conducted to test the normality of distribution (Table 3). All the obtained data had a normal distribution. Moreover, there was a significant positive correlation between the variables. Thus, as the exogenous variables increase, the endogenous variables increase (Table 4).

Table 5 shows the values of $\alpha$ parameters and the coefficients of exogenous variables. Based on the results, the constant values or the $\alpha$ of the 2 exogenous variables (namely

Table 1. Demographics characteristics in hospitals affiliated to Semnan University of Medical Sciences

\begin{tabular}{|c|c|c|}
\hline \multicolumn{2}{|l|}{ Characteristic } & \multirow{2}{*}{$\begin{array}{c}n(\%) \\
43(17.6)\end{array}$} \\
\hline Sex & Male & \\
\hline & Female & $202(82.4)$ \\
\hline \multirow[t]{4}{*}{ Age (years) } & $<25$ & $34(13.9)$ \\
\hline & $25-35$ & 119 (48.6) \\
\hline & $36-45$ & $62(25.3)$ \\
\hline & $>45$ & $30(12.2)$ \\
\hline \multirow[t]{6}{*}{ Experience (years) } & $<5$ & $75(30.7)$ \\
\hline & $5-10$ & $76(31.0)$ \\
\hline & $11-15$ & $39(16.0)$ \\
\hline & $16-20$ & $23(9.4)$ \\
\hline & $21-25$ & $20(48.2)$ \\
\hline & $26-30$ & $12(4.9)$ \\
\hline \multirow[t]{8}{*}{ Position } & Manager & $2(0.8)$ \\
\hline & Specialist physician & $12(4.9)$ \\
\hline & General physician & $6(2.4)$ \\
\hline & Resident & $10(4.1)$ \\
\hline & Supervisor & $8(3.3)$ \\
\hline & Nurse & 190 (77.6) \\
\hline & $\begin{array}{l}\text { Information } \\
\text { technology }\end{array}$ & $4(1.6)$ \\
\hline & Medical records & $13(5.3)$ \\
\hline \multirow[t]{6}{*}{ Education } & Diploma & $6(2.5)$ \\
\hline & Associate & $4(1.6)$ \\
\hline & Bachelor & $4(1.6)$ \\
\hline & Masters & 191 (77.9) \\
\hline & MD & $8(3.3)$ \\
\hline & Specialist & $18(7.4)$ \\
\hline
\end{tabular}

cultural and human resource readiness) are significant $(T>2)$. The regression coefficient of cultural readiness based on organizational readiness is 0.33 . The regression coefficient of human resource readiness based on organizational readiness is 0.14 . When cultural readiness is considered as a mediator variable, the regression coefficient of human resource readiness based on organizational readiness increases by 0.44 .

The predictive coefficient for cultural readiness of hospital staff for implementing RFID technology was significant (Table 6).

Considering the predictive model of human resource readiness for implementing technology and the fact that cultural readiness is influenced by organizational readiness for implementing RFID, it can be observed that 0.346 of the changes of a unit of score for the possibility of implementing RFID under the influence of these 2 variables. This value has a standard deviation of 0.374 .

\section{Discussion}

Organizational readiness had the highest mean (36.84) degree of readiness of the 3 variables. The organizational readiness of the hospitals for the implementation of RFID can play an important role in the successful implementation of this technology. Researchers in the area of information technology systems have emphasized that the secret to the success of this type of technology lies in managerial and organizational dimensions rather than technical and tactical ones [40].

Vanany and Shaharoun found that as organizational support plays a great role in the implementation of new technologies, at the start of the implementation of RFID systems the managers must promote organizational support through the initiation of discussions within the organization. In addition, a framework is needed to be utilized by managers to clearly introduce and explain RFID processes and promote investments and ensure the success of their projects [12]. Thus, organizational readiness will increase the chance of being successful in implementing RFID in the target hospitals.

The results of the present research further showed that a unit of increase in the organizational readiness would lead to 0.576 unit of increase in cultural readiness of the staff members of the hospitals. This finding supports the first hypothesis. However, based on the obtained means, cultural readiness was not as important as organizational readiness. As a result, hospitals should increase commitment to execute their own plans. This commitment will, in turn, raise the commitment of staff. This statement is consistent with the findings of Battani et al., which demonstrate that, for implementing RFID, health organizations should be aware of the reasons for 
Table 2. Descriptive statistics for the 3 research variables

\begin{tabular}{lccccc}
\hline Variable & Mean & Variance & Std. Deviation & Skewness & Kurtosis \\
\hline Human readiness & 25.10 & 12.93 & 3.59 & -0.090 & 0.863 \\
Cultural readiness & 27.95 & 19.49 & 4.41 & -0.447 & 0.574 \\
Organizational readiness & 36.84 & 50.73 & 7.12 & -0.515 & 1.05 \\
\hline
\end{tabular}

Table 3. Kolmogorov-Smirnov test to assess the normality of distribution

\begin{tabular}{lccc}
\hline Variable & Mean & Kolmogorov-Smirnov Z & Asymptotic significance (2-tailed) \\
\hline Human readiness & 25.10 & 1.37 & 0.046 \\
Cultural readiness & 27.95 & 1.15 & 0.141 \\
Organizational readiness & 36.84 & 1.21 & 0.107 \\
\hline
\end{tabular}

its implementation and all levels of the organization should be committed to the plans [41]. Furthermore, hospitals can form a team to include operators in designing RFID, and by so doing, improve staff commitment and teamwork for implementing this technology.

Senior management plays a critical role in RFID implementation [42]. Through their appropriate behavior, managers can promote cultural principles [43], and as a result support the implementation of RFID.

Equally, some changes in duties and responsibilities must be made along with the implementation of the RFID [44] that will result in numerous changes in the working conditions of an organization. Gupta et al. concluded that managers must express their expectations and clarify the possible impact of the new systems on employees' job descriptions and workload as this could encourage the staffs to use new technologies [45].

A study that was conducted at hospitals in Taiwan found that after the implementation of RFID, many changes were made in work processes, manual processes such as data entry, displaying the patient's condition, integration and standardization of operational activities were eliminated, and the efficiency and effectiveness of business processes were increased [18]. Many hospital administrators in Malaysia believed that the implementation of RFID should not make substantial changes in the existing IT systems that they were using [12].

Fisher and Monahan concluded that RFID projects are associated with a reengineering of business processes [5]. Many people are involved in this process and in change management [13]. Fisher and Monahan also argued that prediction of workload increase, assessment of staff's readiness, and involvement in clear negotiation with staff members will lead to staff support for the implementation of RFID and will enhance the chance of its success [5].

It is indisputable that the implementation of RFID technology will result in many changes in the working conditions of employees and organizations. In view of that, by forming executive teams, reengineering working processes, and adopting proper managerial behaviors to manage the processes correctly, hospitals can promote cultural factors such as flexibility among their staff. They can also overcome staff resistance and fear of losing their job as a result of implementing the new technology. They can further enhance a sense of freedom for staff.

Holding appropriate training courses will increase the understanding of staff of the usefulness of RFID, which, in turn, will increase their cooperation and minimize their concerns and resistance. Gupta et al. concluded that training staff along with other facilities such as hardware and software are among the important factors that have a positive effect on the successful implementation of information technology in organizations in countries such as India, which is a developing country. They also stated that organizations need to provide adequate training and support during the process of the implementation and application of information technology systems [45].

For hospitals in South-East Asia, a lack of information was identified as one of the main challenges and obstacles to the implementation of RFID. One study found employees had very little information about this technology; and as a result, they thought the implementation of this system is very difficult and problematic, and thus they resisted the new system. The study suggested that hospitals should train their staff about RFID so that they acquire the required skills and participate more in implementing the new system [12]. Our present results are consistent with these findings.

The present study found that the predictive coefficient of human resource readiness based on cultural readiness for accepting the new technology was significant. More precisely, a unit of increase in cultural readiness would result in a 0.601 unit of increase in human resource readiness. A unit 
of increase in the standard deviation of cultural readiness would lead to 0.671 unit of increase in the standard deviation of human resource readiness. These findings substantiate the second research hypothesis.

Improving the culture of team work and flexibility will positively influence organizational readiness, and will enhance people's motivation and creativity to attain the necessary skills to work with RFID. The results of the present study are similar to those obtained by Szczepańska-Woszczyna who concluded that culture plays a major role in enhancing people's motivation and forming their creative behavior within an organization. They indicated that positive cultural features provide the required conditions for creativity in an organization [46].

The results of the present study show that organizational readiness directly influences human resource readiness, substantiating the third research hypothesis. However, if cultural readiness is considered as a mediator variable, the burden of organizational and human readiness will fall on the cultural readiness, and the impact of organizational readiness on human resource readiness will be reduced, and is transferred to cultural readiness.

Table 4. Pearson correlation between research variables

\begin{tabular}{|c|c|c|c|}
\hline Variable & $\begin{array}{c}\text { Human } \\
\text { readiness }\end{array}$ & $\begin{array}{l}\text { Cultural } \\
\text { readiness }\end{array}$ & $\begin{array}{l}\text { Organizational } \\
\text { readiness }\end{array}$ \\
\hline Human readiness & 1 & & \\
\hline Cultural readiness & $0.664^{* *}$ & 1 & \\
\hline $\begin{array}{l}\text { Organizational } \\
\text { readiness }\end{array}$ & $0.374^{* *}$ & $0.576^{* *}$ & 1 \\
\hline
\end{tabular}

$* * P<0.01$
As shown in Figure 1, considering the cultural factors as mediators, the factor load of organizational and human readiness is added to the variable of culture; moreover, the effect of organizational factors on human factors loses its weight and its load is shifted to cultural factors. Organizational readiness has a more profound effect on human resource readiness by affecting cultural readiness. It is thus claimed that the support of managers and organizations can enhance the cooperation of staff and innovation in the implementation of RFID. Moreover, organizational culture can promote organizational behavior by stimulating and motivating the staff and guiding their behavior. A similar conclusion is reported by Abbasi et al. [47].

The results of the present study should be interpreted with caution because this study was performed just in one city; moreover, only $61.3 \%$ of the eligible study subjects have participated. Hence, caution should be used when generalizing the results to other hospitals. Nevertheless, some of the findings of this study are consistent with the findings of others. Further studies are needed to generalize the results to the entire nation.

\section{Conclusion}

The impact of organizational readiness for implementing RFID is high. Therefore, health information managers will need the support of organization's managers in all the steps of designing and implementing an RFID system as with any other information technology system. Such managers will have complete commitment to the implementation of RFID. To implement RFID, managers should clearly explain their

Table 5. Alpha parameters and the predictive coefficient of human resource readiness based on cultural and organizational readiness and the predictive coefficient of cultural readiness based on organizational readiness

\begin{tabular}{lcccc}
\hline Variable & Constant & $\boldsymbol{T}$ & $\boldsymbol{R}^{\mathbf{2}}$ for structural equations & $\boldsymbol{R}^{\mathbf{2}}$ for reduced form \\
\hline Cultural readiness & 6.73 & 3.52 & 0.332 & - \\
Human readiness & 8.71 & 5.43 & 0.441 & 0.140 \\
\hline
\end{tabular}

Table 6. Direct, indirect, and total estimates of research variables

\begin{tabular}{|c|c|c|c|c|c|c|}
\hline \multirow[t]{2}{*}{ Paths } & \multicolumn{2}{|c|}{ Nonstandard effect } & \multirow{2}{*}{$\frac{\text { Standard effect }}{\text { Effect size }}$} & \multicolumn{2}{|c|}{ Total and nonstandard effect } & \multirow{2}{*}{$\frac{\text { Total standard effect }}{\text { Effect size }}$} \\
\hline & Effect size & $t$ & & Effect size & $t$ & \\
\hline $\begin{array}{l}\text { Organizational readiness to cultural } \\
\text { readiness }(\mathrm{g})\end{array}$ & 0.576 & 11.18 & 0576 & - & - & - \\
\hline $\begin{array}{l}\text { Organizational readiness to human } \\
\text { resource readiness }(\mathrm{g})\end{array}$ & -0.011 & -0.220 & -0.013 & 0.346 & 8.06 & 0.374 \\
\hline $\begin{array}{l}\text { Cultural readiness to human resource } \\
\text { readiness (b) }\end{array}$ & 0.601 & 11.65 & 0.671 & - & - & - \\
\hline
\end{tabular}




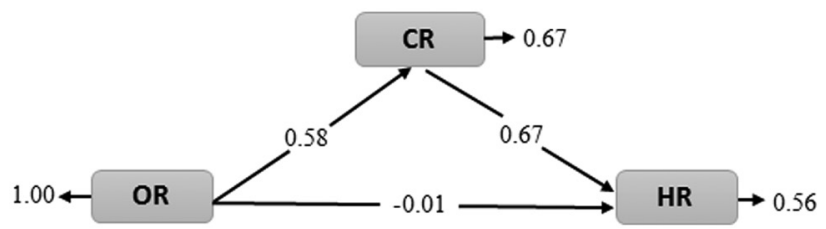

Figure 1. Conceptual model of research variables. OR: organizational readiness. CR: cultural readiness. HR: human readiness

managerial goals, determine the workload of the organization, and plan the necessary steps. They should also pay attention to division of labor in operating and maintaining RFID. Furthermore, managers need to rely on the cooperation of staff in implementing this technology and emphasize group work. The model presented can be regarded as an applied model for managers and programmers in the health area to make decisions and policies for implementing RFID in hospitals within Iran and across developing countries. Equally, cultural factors have greater influence on human resources than any other external factor. Any change in an organization will have no effect unless its organizational culture is taken into consideration. Thus, the culture of an organization must receive attention as an auxiliary tool that facilitates the relationship between human resources and organizational strategies.

The organizational structure and human and cultural factors of the studied hospitals are generally ready for accepting RFID technology. The data analysis revealed that cultural factors play a significant role in implementing RFID projects in developing countries like Iran. Concentrating more on cultural factors will minimize the risk of failure in implementing RFID. As a result, hospitals should strengthen organizational factors and enhance the support of top rank managers' support for implementing RFID. By so doing, they will promote cultural readiness, prepare human resources, and win the cooperation of the personnel in implementing such a technological project. Overlooking these factors and their significant effect on each other, even when the project has a strong technical base, may lead to a malfunction in the implementation of RFID and may ultimately lead to project failure.

Author contributions. MS and MK contributed substantially to the conception and design of the study, ZR and EG collected the data, and PR and MS analyzed and interpreted it. MS, ZR, EG, and MK drafted the original manuscript, and MS, PR, and MK critically revised it. All authors approved the final version of the manuscript submitted for publication and take responsibility for the statements made in the published article.

Acknowledgments. We thank all participants in this study. We also thank the Research Council, and Clinical Research
Development Unit of Koosar and Amir-al Moamenin Hospital for providing facilities for this work. Research reported in this publication was supported by a grant (no. 764) from the Semnan University of Medical Sciences, Semnan, Iran.

Conflicts of interest. The authors have each completed an International Committee for Medical Journal Editors Form for Disclosure of Potential Conflicts of Interest. No authors have anything to disclose.

\section{References}

[1] Halili SH, Sulaiman H. Factors influencing the rural students' acceptance of using ICT for educational purposes. Kasetsart J Soc Sci. 2018; 19:1-6.

[2] Aguado Correa F, Álvarez Gil MJ, Barcos Redín L. RFID and health management: is it a good tool against system inefficiencies? Int J Healthcare Technol Manag. 2007; 8:268-97.

[3] Owunwanne D. Radio Frequency Identification (RFID) technology: gaining a competitive value through cloud computing. Int J Manag Inf Syst. 2016; 20:37-44.

[4] Haddara M, Staaby A. RFID Applications and adoptions in healthcare: a review on patient safety. Procedia Comput Sci. 2018; 138:80-8.

[5] Fisher JA, Monahan T. Tracking the social dimensions of RFID systems in hospitals. Int J Med Inform. 2008; 77:176-83.

[6] Sun C. Application of RFID technology for logistics on internet of things. Am Appl Sci Res Inst Procedia. 2012; 1:106-11.

[7] Madanian S. The use of e-health technology in healthcare environment: the role of RFID technology. Proceedings of the 10th International Conference e-Commerce in Developing Countries: with focus on e-Tourism; 2016 April 15-16; Isfahan, Iran. New York: IEEE; 2016. 978-1-5090-2172-7/16

[8] Ko CH. Information technology in engineering and project management. J Engineering, Project, and Production Management. 2017; 7:1.

[9] Aboelmaged M, Hashem G. RFID application in patient and medical asset operations management: A technology, organizational and environmental (TOE) perspective into key enablers and impediments. Int J Med Inform. 2018; 118:58-64.

[10] Rahman F, Bhuiyan MdZA, Ahamed SI. A privacy preserving framework for RFID based healthcare systems. Future Generation Computer Systems. 2017; 72:339-52.

[11] Álvarez López Y, Franssen J, Álvarez Narciandi G, Pagnozzi J, González-Pinto Arrillaga I, Las-Heras Andrés F. RFID Technology for management and tracking: e-health applications. Sensors. 2018; 18:2663. doi:10.3390/s18082663

[12] Vanany I, Shaharoun ABM. Barriers and critical success factors towards RFID technology adoption in South-East Asian healthcare industry. Proceedings of The 9th Asia Pacific Industrial Engineering \& Management Systems Conference; 2008 December 3-5; Bali, Indonesia. p. 144-55.

[13] Moatari-Kazerouni A, Bendavid Y. Improving logistics processes of surgical instruments: case of RFID technology. Business Process Management Journal. 2017; 23:448-66. 
[14] Louw L, Walker M. Design and implementation of a low cost RFID track and trace system in a learning factory. Procedia Manufacturing. 2018; 23:255-60.

[15] Hu L, Ong DM, Zhu X, Liu Q, Song E. Enabling RFID technology for healthcare: application, architecture, and challenges. Telecommun Syst. 2015; 58:259-71.

[16] Lee YH, Marsic I. Object motion detection based on passive UHF RFID tags using a hidden Markov model-based classifier. Sens Biosensing Res. 2018; 21:65-74.

[17] Duroc Y, Tedjini S. RFID: a key technology for humanity. Comptes Rendus Physique. 2018; 19:64-71.

[18] Tzeng S-F, Chen W-H, Pai F-Y. Evaluating the business value of RFID: Evidence from five case studies. Int J Production Economics. 2008; 112:601-13.

[19] Attaran M. Critical success factors and challenges of implementing RFID in supply chain management. J Supply Chain Oper Manag. 2012; 10:144-67.

[20] Carr AS, Zhang M, Klopping I, Min H. RFID technology: implications for healthcare organizations. Am J Bus 2010; 25:25-40.

[21] Ebrahimi S, Sharifian R, Bastani P. Readiness of hospitals affiliated with Shiraz University of Medical Sciences for implementation of radio frequency identification technology. J Health Man Inform. 2015; 2:120-5.

[22] Peris-Lopez P, Orfila A, Mitrokotsa A, Van der Lubbe JC. A comprehensive RFID solution to enhance inpatient medication safety. Int J Med Inform. 2011; 80:13-24.

[23] van der Togt R, Bakker PJ, Jaspers MWM. A framework for performance and data quality assessment of Radio Frequency IDentification (RFID) systems in health care settings. J Biomed Inform. 2011; 44:372-83.

[24] Juels A. RFID security and privacy: a research survey. IEEE Journal on Selected Areas in Communications. 2006; 24:381-94.

[25] Jokar A, Nasir-Zenosi A. [Factors affecting RFID technology adoption in Iran industries]. Industrial Management Vision. 2013; 8:117-41. [In Persian]

[26] Hosseini SM, Tabibi SJ, Nasiripour AA, Sepehri MM. [The readiness of hospitals to implement RFID technology]. Int J Travel Med Glob Health. 2015; 3:103-5. [In Persian]

[27] Najaf Beyki R. [Culture and Development in the Third World]. Journal of Economy an Management. 2006; 68:25-32. [In Persian]

[28] Leidner DE, Kayworth T. A review of culture in information systems research: toward a theory of information technology culture conflict. MIS Q. 2006; 30:357-99.

[29] Kwantes CT, Boglarsky CA. Perceptions of organizational culture, leadership effectiveness and personal effectiveness across six countries. J Int Manag 2007; 13:204-30.

[30] Khaef Elahi A, Rajabzadeh A, Lajavardi A. [Presentation of human resources modeling with emphasis on the role of new technologies]. Journal of Human Resource Management. 2010; 2:1-26. [In Persian]

[31] Kijsanayotin B, Pannarunothai S, Speedie SM. Factors influencing health information technology adoption in Thailand's community health centers: applying the UTAUT model. Int J Med Inform. 2009; 78:404-16.
[32] Asgarian M. [The concept of corporate culture]. Police Bimonthly Human Development Journal. 2009: 101-24. [In Persian]

[33] da Veiga A, Martins N, Eloff JHP. Information security culture-validation of an assessment instrument. Southern African Business Review. 2007; 11:147-66.

[34] Gunnigle P, Moore S. Linking business strategy and human resource management: issues and implications. Personnel Review. 1994; 23:63-84.

[35] Roshandel Arbatani T, Saber M. [The relationship between information and communication technology culture and Internet culture injuries]. Interdisciplinary Studies in Media and Culture Institute for Humanities and Cultural Studies. 2013; 2:109-28. [In Persian]

[36] Fathizadeh S, Daneshfard K, Parsaziabari L. [Organizational culture, absorption capacity and IT implementation successful]. Journal of Public Management Mission. 2012; 2:73-86. [In Persian]

[37] Aarabi M, Moghadam A. [Coordinating human resources strategy with business strategy and organizational culture]. Journal of Management Science Iran. 2008; 2:103-35. [In Persian]

[38] Suen H-Y, Chang H-L. Toward multi-stakeholder value: virtual human resource management. Sustainability. 2017; 9:2177. doi:10.3390/su9122177

[39] MacMillan IC. New business development: a challenge for transformational leadership. Human Resource Management 1987; 26:439-54.

[40] Sabeti M, Nabavi M. [Identifying and ranking critical success factors in the transfer of technology information systems in the automotive industry of Iran]. Fourth National Conference on Technology Management of Iran. Journal Parks Growth Center. 2012; 26: 1-13. [In Persian]

[41] Battini D, Faccio M, Persona A, Sgarbossa F. A new methodological framework to implement an RFID project and its application. International Journal of RF Technologies: Research and Applications. 2009; 1:77-94. doi:10.1080/17545730802320174

[42] Yao W, Chu CH, Li Z. The adoption and implementation of RFID technologies in healthcare: a literature review. J Med Syst. 2012; 36:3507-25.

[43] Sanjaghi ME, Farahi Bozanjani B, Hoseyni Sarkhosh M. [The effect of mediated culture of adaptability on the relationship between transformational leadership and organizational innovation]. Management Improvement Journal. 2014; 5:122-39. [In Persian]

[44] Oreg S. Personality, context, and resistance to organizational change. Eur J Work Organizational Psychology 2006; 15:73-101.

[45] Gupta B, Dasgupta S, Gupta A. Adoption of ICT in a government organization in a developing country: An empirical study. J Strateg Inf Syst. 2008; 17:140-54.

[46] Szczepańska-Woszczyna K. Leadership and organizational culture as the normative influence of top management on employee's behaviour in the innovation process. Procedia Econ Finance. 2015; 34:396-402.

[47] Abbasi R, Babashahi J, Afkhami Ardekani M. [The impact of flexibility of human resources on entrepreneurship: clarifying the role of mediator culture of adaptability]. Journal of Culture Management. 2014; 11:87-106. [In Persian]. 